\title{
Erratum to: Effusive Reasoning
}

Brandon Erickson, $B S^{7}$, Gurpreet Dhaliwal, $\mathrm{MD}^{2}$, Mark C. Henderson, $\mathrm{MD}^{3}$, Ezra Amsterdam, MD ${ }^{4}$, and Joseph Rencic, MD, FACP ${ }^{1,5}$

${ }^{1}$ Tufts University School of Medicine, Boston, MA, USA; ${ }^{2}$ Department of Medicine, University of California, San Francisco and the San Francisco Veterans Affairs Medical Center, San Francisco, CA, USA; ${ }^{3}$ Department of Internal Medicine, University of California, Davis Medical Center, Sacramento, CA, USA; ${ }^{4}$ Department of Internal Medicine, Division of Cardiovascular Medicine, University of California, Davis Medical Center, Sacramento, CA, USA; ${ }^{5}$ Department of Internal Medicine, Tufts Medical Center, Boston, MA, USA.

J Gen Intern Med 26(10):1235

DOI: $10.1007 / \mathrm{s} 11606-011-1846-\mathrm{y}$

(c) Society of General Internal Medicine 2011

$\mathrm{O}$

n page 4 of the original publication, the first sentence of the final paragraph of the Discussion reads: "The framework assumes that the ultimate unifying diagnoses are mutually exclusive." The revised version should read: "The $\sum \mathrm{P}(\mathrm{Dx})=\mathrm{P}(\mathrm{Dx} 1)+\mathrm{P}(\mathrm{Dx} 2)+\mathrm{P}(\mathrm{Dx} 3)=100 \%$ framework assumes that the ultimate unifying diagnoses are mutually exclusive."

The online version of the original article can be found at $h$ ttp://dx.doi. org/10.1007/s11606-011-1785-7.

Published online September 3, 2011 